\section{SPRU}

Science and Technology

Policy Research
Working Paper Series

SWPS 2013-11

October, 2013

\title{
Processes of firm growth and diversification: theory and evidence
}

Alex Coad and Christina Guenther 


\section{SPRU Working Paper Series}

The SPRU Working Paper Series aims to accelerate the public availability of the research undertaken by SPRU-associated people of all categories, and exceptionally, other research that is of considerable interest within SPRU. It presents research results that in whole or part are suitable for submission to a refereed journal, to a sponsor, to a major conference or to the editor of a book. Our intention is to provide access to early copies of SPRU research.

\section{Editors}

Tommaso Ciarli

Daniele Rotolo

\section{Associate Editors}

Florian Kern

Paul Nightingale

Matias Ramirez

Joe Tidd \&

Carlos Sato

Maria Savona \&

Mariana Mazzucato

Andrew Stirling Transitions

Caitriona McLeish

Civil military interface

Area

Energy

\section{Contact}

T.Ciarli@sussex.ac.uk

D.Rotolo@sussex.ac.uk

F.Kern@sussex.ac.uk

P.Nightingale@sussex.ac.uk

Matias.Ramirez@sussex.ac.uk

J.Tidd@sussex.ac.uk

C.E.Y.Sato@sussex.ac.uk

M.Savona@sussex.ac.uk

M.Mazzucato@sussex.ac.uk

A.C.Stirling@sussex.ac.uk

C.A.McLeish@sussex.ac.uk

J.Lieu@sussex.ac.uk

Administrator

Jenny Lieu

\section{Disclaimer}

The works available here are the responsibility of the individual author(s) and do not necessarily represent the views of other SPRU researchers. As matters of policy and practice, SPRU does not endorse individual research contributions.

\section{Guidelines for authors}

Papers shall be submitted in pdf or Word format. They should contain a title, an abstract, and keywords. Papers should be submitted to one of the Editors, who will process them and send them to the appropriate Associate Editor. Two members of SPRU will be asked to provide a short written review within three weeks. The revised versions of the paper, together with a reply to the reviewers, should be sent to the Associate Editor, who will propose to the Editors its publication on the series. When submitting the authors should indicate if the paper has already undergone peerreviewing, in which case the Associate Editors may decide to skip internal review process.

\section{Website}

SWPS: www.sussex.ac.uk/spru/research/sewps

IDEAS: ideas.repec.org/s/sru/ssewps.html 


\title{
Processes of firm growth and diversification: theory and evidence $^{1}$
}

\author{
Alex Coad (CONTACT AUTHOR) \\ SPRU - Science and Technology Policy Research, BMEC \\ Jubilee Building 379, University of Sussex \\ Falmer, Brighton, BN1 9SL, UK \\ A.Coad@sussex.ac.uk \\ Christina Guenther \\ WHU-Otto Beisheim School of Management, \\ Burgplatz 2, 56179 Vallendar, Germany. \\ Christina.Guenther@whu.edu
}

This version: 24 October 2013

\begin{abstract}
In this short research note we investigate the role of diversification in the firm growth process. We build on Penrose's (1959) Theory of the Growth of the Firm to formulate hypotheses about growth of employment, assets, and sales in the years before, during and after a new product introduction. We exploit a new database from the German machine tool industry which boasts a detailed and meaningful definition of diversification. Our exploratory analyses indicate that diversification, in terms of product introductions, is preceded by employment growth. Moreover, we find support that diversification is positively associated with subsequent asset growth, but negatively associated with subsequent employment growth.
\end{abstract}

JEL CODES: L6, L11, L20, L25

KEYWORDS: Diversification, Firm growth, Penrose, Machine tools, Growth process

\footnotetext{
${ }^{1}$ We are grateful to Agusti Segarra, Mercedes Teruel, and participants at the workshop on "Firm Growth and Innovation" (Tarragona, June 2012), as well as to two anonymous referees, for many helpful comments and suggestions. Alex Coad gratefully acknowledges financial support from the ESRC, TSB, BIS and NESTA on grants ES/H008705/1 and ES/J008427/1 as part of the IRC distributed projects initiative, as well as from the AHRC as part of the FUSE project. The usual caveat applies.
} 


\section{INTRODUCTION}

The processes of firm growth have attracted public and scholarly attention as they represent key factors for job creation (e.g. Haltiwanger et al, 2013; Huber et al., $2012 \mathrm{a}, \mathrm{b}$ ) and also contribute to productivity growth (Foster et al, 2006). But even though firm growth and diversification have been investigated for several decades by now, we still lack a clear understanding of firm growth patterns and their link with diversification. Traditionally, work on firm growth has focused on indicators such as sales and employment growth (Delmar, 1997). But these indicators are rather limited in their power to uncover the underlying processes of firm growth and diversification as well as their interdependencies.

McKelvie and Wiklund (2010) advocate that there is a need to move away from looking at "how much" firms grow, but instead looking at "how" firms grow - that is, looking beyond the quantitative growth rate variable to investigate the qualitative dimensions of firm growth. Firm growth is well-approximated by a random walk process, and it has been observed that there is more variation in growth rates within firms over time, than across firms (Geroski and Gugler, 2004). Relatedly, Penrose observed that "growth can take place in spurts, and periods of relative decline may well be followed by periods of accelerated growth" (Penrose 1995, p.213). As a result, there is a need to focus on variables that are not time-invariant or slow-moving, but that display considerable change over time within individual firms. In the endeavour to combine these requests, emphasis has recently been placed on 'trigger points' (such as diversification or internationalization) where firms are faced with the immediate decision of whether they will grow or not (Brown and Mawson, 2013). In this context, firm growth by diversification is closely related to innovation: "In a sense, diversification is similar to innovation because a firm adds an activity that is new from the firm's perspective, even though the activity itself may not be new to the world" (Neffke and Henning, 2013, p311). When a firm diversifies, it introduces a new product and faces considerable uncertainty in the hope of enjoying gains. Diversification is sometimes taken as a meaningful indicator of innovation (output) that can complement existing work on traditional measures such as R\&D and patents. Indeed, European CIS innovation surveys confound innovation and diversification by asking firms if they have introduced 'products new to the firm' - which is of course the essence of diversification. Although diversification does not necessarily imply innovation ${ }^{2}$, we consider that investigating the relationship between firm growth and diversification can help improve our understanding of innovation and its stimulating effect on firm growth. However, the relationship between new product introductions and the growth of innovative firms has received little attention in previous work (Balasubramanian and Sividasan, 2011).

\footnotetext{
${ }^{2}$ For example, diversification might correspond to imitation rather than innovation, and furthermore firms might diversify as part of a managerial 'empire-building' strategy, or perhaps to minimize risk, which are not attempts at innovation. We are grateful to a referee for pointing this out.
} 
The idea that diversification increases firm performance and leads to firm growth on various dimensions such as sales and employment is of course not new (e.g. Palich et al, 2000). But within these studies two aspects of the diversification-growth linkage have been neglected so far. First, as the focus is on diversification as a trigger for growth there is no explicit empirical or theoretical consideration integrating the firm's situation preceding the diversification event. Second, there is generally no differentiation between the various growth indicators and their development around the diversification event. In this paper, we seek to address these challenges to the firm growth literature by looking at the characteristics and effects of firm-level diversification events. We propose a theoretical framework that differentiates between the various growth indicators as well as their development before, during and after the diversification event using Penrosean growth theory. Moreover, we present some preliminary indicative empirical results by testing our theoretical framework for the case of the German machine tool industry between 2000 and 2010. We thereby build on previous work investigating diversification patterns within this single industry setting (Coad and Guenther, 2013).

The paper proceeds as follows: we begin with a theoretical discussion of the role of diversification as a growth event, and how it is inter-related with growth of employment, sales and assets before, during, and after diversification. Section three introduces our dataset before we test the derived hypotheses in section four. Section five concludes.

\section{Theory}

\subsection{Overview of Penrose's schema}

We develop our hypotheses by referring to Penrose's (1959) influential theory of firm growth and diversification. Penrose considered that growth was not just aimless organizational drift, but was deliberate and required careful planning: "failure to grow is often incorrectly attributed to demand conditions rather than to the limited nature of entrepreneurial resources" (p37). Diversification, in particular, requires much careful planning.

A key input into the growth process is managerial attention, which can be focused in any of three areas: learning about existing operations, training up new hires, or planning for growth. To begin with, managers must focus their attention on learning about existing operations - "Individuals taking over executive functions new to them will find that many things are problems merely because of their relative unfamiliarity" (p52), but that as managers become more accustomed to a firm's operations their productivity improves. Firms learn how to maintain their existing positions in markets and how to satisfy their demand. As time goes by, they become more secure in existing business activities. Firms become more familiar with their everyday demands, and as 
they learn to deal with production of existing goods/services in a routinized and semiautomatic way, managerial attention and capacity is released, which allows them to focus on training new managers, or planning for growth (through diversification).

Penrose's vision of firm growth is knowledge-based and centred on a management "team" learning to work together and learning about available growth opportunities "the very processes of operation and of expansion are intimately associated with a process by which knowledge is increased" (p56). Experience of the management team is key: "the experience of a firm's managerial group plays a crucial role in the whole process of expansion" ( $\mathrm{p} 48$ ). The management team must gather information about their idiosyncratic resources and how their firm fits in the market environment, digest it, select the most desirable growth opportunities, and make a decision about a growth plan. It may even be the case that diversification provides the impetus for further (organic) growth, as firms try to internalize and make use of their newly acquired resources and capabilities (cf Lockett et al, 2011).

\subsection{Prior to diversification}

There are a number of different modes of growth by which firms can carry out their growth plans: growth in existing submarkets, expansion into new regions (intranational, or international), M\&As to rapidly acquire production capacity or strategic assets, and diversification into new product markets. Diversification is only one particular mode of growth that involves a relatively high degree of uncertainty - firms may instead choose less risky growth strategies such as pursuing scale economies within existing submarkets. This latter group of firms will invest in process innovations and capital as they seek to grow within existing submarkets. This leads us to suggest that growth of assets is relatively low for firms planning new product introductions.

Planning for growth will require plenty of managerial thought, which requires using internal resources as well as integrating external resource and expertise - that is, adding new human resources prior to diversification ${ }^{3}$. Even though the externally recruited resources and new employees are essential to realize the expansion, it will take time to train up these new employees before they become familiar enough with the business environment to draw up valuable growth plans. There is therefore a tension between planning for growth and training up new employees - "the amount of activity that can be planned at a given time limits the amount of new personnel that can profitably be absorbed in the 'next period'" (Penrose, 1959, p49). Thus, once these new employees have been added, their attention will be directed towards first learning about the ways of the firm, and then drawing up growth plans for diversification.

\footnotetext{
${ }^{3}$ In our context diversification refers to the commercialization stage of a new product introduction, i.e. offering a new product. This new product will certainly be new to the firm, but does not necessarily have to be new to the industry in which the firm operates.
} 
Firms may have a 'pecking order' according to which they first choose the low-risk, easier option of higher sales in existing submarkets. However, this cannot continue indefinitely. Market becomes saturated. There are limits to growth in existing submarkets. Sales may therefore dwindle as a firm recognizes the limits to growth in existing markets and considers further growth through diversification. Also, there may be weak investment before diversification (because firms don't want to invest heavily in existing submarkets in which opportunities are limited). However, employment doesn't have a commensurate decline, because slack human resources (in the form of managerial attention) are instead redirected to planning for growth through diversification.

Hypothesis 1a: Employment growth will be significantly higher in the year preceding diversification

Hypothesis 1b: Assets growth will be significantly lower in the year preceding diversification

Hypothesis 1c: Sales growth will be significantly lower in the year preceding diversification

In Hypotheses 1a-1c, and also for our subsequent hypotheses, the words "significantly higher" and "significantly lower" refer to the control group of firm-year observations that are not associated with new product introduction events. These firm-year observations in the control group come primarily from non-diversifying firms, but can also correspond to firm-year observations of diversifying firms in the years that they are not engaged in new product introductions. ${ }^{4}$

\subsection{The time of diversification}

According to Penrose, it takes time and effort to internalize new employees. Managerial attention is needed to train new employees. At the time of diversification, managerial attention goes towards growth plans, not new hires - and so we expect that employment growth in the year of diversification will be low. In addition to human resources, diversification will require investment in assets. At the time of diversification, firms are likely to invest in assets. While it takes time to internalize human resources, it is considered by Penrose to be less of an issue for investment in assets (unless it takes an unusually long time to install the new capital stock).

At the time of diversification, firms will start to offer new products, and hence will have a larger range of products. They will continue to receive income from existing products,

\footnotetext{
${ }^{4}$ Our implicit benchmark growth model for non-diversification events is Gibrat's model of random growth shocks, according to which a firm's growth rate has expected value $\mu$ and standard deviation $\sigma$. We therefore take as the growth rate of the control group the growth rate of all firms that are not undergoing a diversification event (i.e. the growth rate of the control group is $\mu$ ).
} 
plus new sales from new products. Therefore sales can be expected to increase at the time of diversification.

Hypothesis 2a: Employment growth will be significantly lower in the year of diversification

Hypothesis 2b: Assets growth will be significantly higher in the year of diversification Hypothesis 2c: Sales growth will be significantly higher in the year of diversification

\subsection{Consequences of diversification}

Once the diversification event has taken place, the firm will offer a new product on the market place and can therefore be expected to enjoy higher sales. After diversification, however, firms will be stretched for resources and will put all available managerial attention on learning about the new submarket in order to further establish themselves in the newly entered field. After diversification, the organization will slowly build up capabilities in the new market. Managers will gain experience and become more productive as they learn more about the new submarket in terms of production as well as customers, contributing to gradual improvements in sales. This learning process will result in increasing labour productivity (i.e. a higher output per worker ratio) as existing employees become more efficient. We also hypothesize that the asset stock will continue to grow in the year after diversification, because firms may need to keep on investing in (tangible and intangible) assets after the product has been formally introduced. This could be because of the time taken to adjust a firm's asset stock (adjustment costs) as well as due to knock-on effects of new investments requiring further investment in complementary areas.

While we expect that sales will grow after the diversification event, we do not expect there to be employment growth after the diversification event - instead existing workers are now prepared for being active in the new sector and employment reaches a plateau. It takes time for new workers to be trained up and internalized, and furthermore, new hires would be a distraction to existing employees who should focus on carrying out their diversification plans rather than training new employees. ${ }^{5}$ Although it may be the case that further hires are needed (especially at the lower 'bluecollar' levels) to help execute the diversification plans, nonetheless we hypothesise as follows:

Hypothesis 3a: Employment growth will be significantly lower in the year after diversification

Hypothesis 3b: Assets growth will be significantly higher in the year after diversification Hypothesis 3c: Sales growth will be significantly higher in the year after diversification

\footnotetext{
5 It may be the case that further hires are needed to help execute the diversification plans, however, if the firm was ill-prepared for the growth event, or if the firm seeks to recruit employees at the lower 'bluecollar' levels, where new hires can be hired more easily (less distraction for managers) and can quickly learn their tasks (and quickly reach a high state of productivity).
} 
For an overview of the hypothesized effects, see Table 1.

Table 1: Hypothesis matrix: Summary of expected effects

\begin{tabular}{|l|l|l|l|}
\hline & \multicolumn{4}{l|}{ New product introduction } & H3: After \\
\hline & H1: Prior & H2: During & - \\
\hline a) Empl. growth & + & - & + \\
\hline b) Assets growth & - & + & + \\
\hline c) Sales growth & - & + & \\
\hline
\end{tabular}

\section{DATA}

Penrose focused on the case of growth through diversification. In her view, "There are very few, if any, completely undiversified firms if 'product,' and especially 'intermediate product,' is defined narrowly [...] diversification is almost a necessity, in the sense that no firm would expect to compete successfully if it did not produce at least a minimum product line" (1959, p111). A key challenge, however, is finding clean measures of diversification. We do this by focusing on the machine tools industry. For the upcoming empirical investigation we combine three main data sources. Our primary dataset builds on the German machine tool buyer's guide "Who makes machinery" published by the Verein Deutscher Maschinen-und Anlagenbauer (VDMA). This source allows us to identify the entire firm population of machine tool producers in Germany for our investigation period from 2000 until 2010.6 For each of the identified 821 machine tool producers (excluding service or retail companies) we constructed an annual product portfolio using the same data source. More precisely, the catalogue does not only differentiate between the major product categories according to the underlying machining procedures, i.e. metal cutting, forming, separating, or special purpose machinery, but it distinguishes between more than 1200 individual products such as belt grinding machines, pillar-type drilling machines, or arbor presses. Based on this fine-grained classification scheme, we count all products per firm per year in a first step.

In a second step we compare the annual product portfolios for each firm and identify the diversification events. For our empirical analysis we define a diversification event as follows: Based on our major source, a firm is considered to have diversified into a new product market within the industry, if it is listed as a supplier in a product market, in which it has not been listed before. ${ }^{7}$ We assign the diversification event to the year in which the firm was first listed in this additional product market. Using this approach

\footnotetext{
6 This source and the corresponding classification scheme has already proven to be suitable for studying the market, regional, and firm-level dynamics within this industry for the post-war era until the end of the last century (Fornahl and Guenther, 2010; Buenstorf and Guenther, 2011; Falck et al. 2013; Coad and Guenther, 2012).

${ }^{7}$ If a firm re-enters a product market in which it was previously active, this is not counted as a new product introduction in our data. Moreover, we used the database M\&A Mergerstat to rule out the possibility of mergers and acquisitions for the considered companies in this time period (which might give rise to diversification events following other dynamics than outlined in the theory section).
} 
based on first time listings to identify intra-industry diversification we follow earlier work in the field of industry and diversification studies (e.g. Klepper and Sleeper, 2005; Buenstorf and Klepper, 2009; Rawley, 2010), which identified inter-industry diversifiers in a similar way. Thus, this definition focusses on the commercialization of a product and not on its development stage. ${ }^{8}$ After this first dataset was built we used a second data source to gather additional firm-specific information with respect to firm size and growth in terms of employees, sales and assets. For this purpose we matched our list of 821 machine tool producers with the MARKUS and DAFNE databases by Bureau van Dijk. Unfortunately, these databases do not offer the necessary information for all companies over the entire time period. Thirdly, we retrieved annual patent data for each firm via Depatisnet, to take into account the (relatively under-researched) link between patenting and new product introductions (Balasubramanian and Sividasan, 2011).

With regards to our measure of firm growth, we sympathise with Penrose (1959, p199) that "there is no way of measuring an amount of expansion, or even the size of a firm, that is not open to serious conceptual objections" - whether it be in terms of number of employees or assets or sales. Each indicator has its drawback, and furthermore, each indicator sheds light on a quite different facet of the growth process. Penrose's analysis is most directly applicable to growth as measured in fixed assets (Penrose, 1959, p25), although employment is of course an important indicator given Penrose's emphasis on human resources. We also include sales growth because prior empirical work on firm growth has shown a preference for this growth indicator. In the upcoming analysis we therefore concentrate on the following variables: growth rates of sales, employment, and total assets, which are calculated in the usual way by taking log-differences (Coad, 2009). Investigating the changes in the annual product portfolio allows us to identify the number of product introductions per firm per year as explained above.

Concerning our control variables, these were generally chosen with regards to the information available to us, as well as to factors that have been identified as being important in prior literature. As control variables, we have dummies for each year, as well as for 97 regions ("Raumordnungsregionen": regional planning districts) to control for the possibility that firms' diversification propensity and growth might be influenced by business cycle effects or location (dis-)advantages. On top of the region-level information we measure the potential regional impact, i.e. intra-industry knowledge spill-overs and externalities by the absolute number of machine tool producers (Marshall, 1920) as well as the regions' population density (Jacobs, 1969). Moreover, we include the number of universities of applied sciences ${ }^{9}$ in the same region as regional proximity to research institutions has been shown to strongly contribute to a region's

\footnotetext{
${ }^{8}$ Note that we do not investigate other modes of diversification, such as international expansion. For an investigation of firm growth in multinational corporate groups, see Oberhofer and Pfaffermayr (2013). 9 We also had information on other higher education institutes (that is, number of universities, and music and arts colleges), but since these latter institutes were less theoretically relevant than universities of applied science, and furthermore were not significant in our preliminary analyses, we did not include them in our regressions reported here.
} 
innovation processes in the manufacturing sector via co-operations (e.g. Fritsch and Schwirten, 1999). Moreover, we gathered information about the original founding dates of the individual companies either from the buyer's guide directly or the firms' homepages, as prior studies have shown that growth through diversification depends on firm age (Coad and Guenther, 2013). Before proceeding with our analysis, we cleaned the data. Data entry mistakes (such as duplicates) are investigated one-by-one, duplicates are dropped, and our data were thus arranged in panel format.

\section{ANALYSIS}

Table 2 contains some summary statistics, for different groups of firms based on the number of product introductions. Most firms have zero product introductions - new product introductions do not occur very often. When we do observe a diversification event, we essentially have one such event per firm, for those firms that do diversify. ${ }^{10}$ Those firms with 1 or more product introductions are larger than those with zero product introductions, in terms of sales, employees, assets, and number of products. They also have more patents. Table 2 also presents a breakdown of summary statistics according to whether a firm ever diversifies during our period of observation (bottom two panels). Those who diversify at least once are larger, and have more products and patents than those firms who never diversify.

Table 2 also contains summary statistics for the annual growth rates of sales, employment and assets. Comparing diversification years (Product intro $>=1$ ) to nondiversification years (Product intro $=0$ ), we can see that diversification years are periods of seemingly higher sales growth (0.133 vs 0.028$)$ and higher assets growth (0.124 vs 0.063 ) but lower employment growth (-0.002 vs 0.018). ${ }^{11}$ However, looking at the lower two panels of Table 2 we see that firms that diversify at least once during the period of observation are similar to those who never diversify during the period of observation. This suggests that we should look at the overall effects of diversification on growth by also taking into account the years prior to diversification (planning for growth) and after diversification (executing growth plans).

\footnotetext{
10 This is indicated by the fact that the number of observations is essentially the same as the number of firms in the lower panel of Table 2 that corresponds to $>=1$ product introduction events.

11 Two-sample t-tests of unequal variance show that these differences are not statistically significant, however.
} 
Table 2: Summary statistics

\begin{tabular}{|c|c|c|c|c|c|}
\hline Variable & Obs & Mean & Std. Dev. & Min & Max \\
\hline \multicolumn{6}{|l|}{ FULL SAMPLE } \\
\hline Sales & 1515 & 82830 & 251350 & 0 & 3185000 \\
\hline Empl & 1313 & 416 & 1076 & 1 & 9648 \\
\hline Assets & 1355 & 55854 & 173475 & 25 & 1862241 \\
\hline Number of products & 3827 & 3.11 & 3.43 & 0 & 28 \\
\hline Patents & 3019 & 1.08 & 3.11 & 0 & 59 \\
\hline Sales growth & 1116 & 0.029 & 0.478 & -6.824 & 6.808 \\
\hline Empl growth & 926 & 0.018 & 0.341 & -3.439 & 4.868 \\
\hline Assets growth & 1003 & 0.064 & 0.476 & -3.570 & 6.983 \\
\hline \multicolumn{6}{|l|}{ PRODUCT INTRO = 0} \\
\hline Sales & 1488 & 81428 & 248347 & 0 & 3185000 \\
\hline Empl & 1297 & 411 & 1066 & 1 & 9648 \\
\hline Assets & 1327 & 54706 & 170843 & 25 & 1862241 \\
\hline Number of products & 3728 & 3.00 & 3.30 & 0 & 28 \\
\hline Patents & 2935 & 1.05 & 3.04 & 0 & 59 \\
\hline Sales growth & 1102 & 0.028 & 0.480 & -6.824 & 6.808 \\
\hline Empl growth & 915 & 0.018 & 0.342 & -3.439 & 4.868 \\
\hline Assets growth & 984 & 0.063 & 0.473 & -3.570 & 6.983 \\
\hline \multicolumn{6}{|l|}{ PRODUCT INTRO >= 1} \\
\hline Sales & 27 & 160107 & 380936 & 1400 & 1903964 \\
\hline Empl & 16 & 877 & 1703 & 9 & 6051 \\
\hline Assets & 28 & 110251 & 269399 & 120 & 1390358 \\
\hline Number of products & 99 & 7.27 & 5.25 & 1 & 28 \\
\hline Patents & 84 & 2.13 & 5.06 & 0 & 29 \\
\hline Sales growth & 14 & 0.133 & 0.300 & -0.269 & 0.992 \\
\hline Empl growth & 11 & -0.002 & 0.091 & -0.220 & 0.117 \\
\hline Assets growth & 19 & 0.124 & 0.644 & -0.762 & 2.587 \\
\hline \multicolumn{6}{|l|}{ NEVER DIVERSIFY } \\
\hline Sales & 1213 & 64614 & 224965 & 0 & 3185000 \\
\hline Empl & 1045 & 363 & 1025 & 1 & 9648 \\
\hline Assets & 1079 & 43218 & 151352 & 25 & 1862241 \\
\hline Number of products & 3158 & 2.69 & 2.73 & 0 & 26 \\
\hline Patents & 2438 & 0.81 & 2.10 & 0 & 36 \\
\hline Sales growth & 879 & 0.030 & 0.501 & -6.824 & 6.808 \\
\hline Empl growth & 727 & 0.013 & 0.325 & -3.439 & 3.434 \\
\hline Assets growth & 790 & 0.063 & 0.495 & -3.570 & 6.983 \\
\hline \multicolumn{6}{|c|}{ DIVERSIFY AT LEAST ONCE } \\
\hline Sales & 302 & 155995 & 327540 & 135 & 2144038 \\
\hline Empl & 268 & 624 & 1236 & 1 & 7769 \\
\hline Assets & 276 & 105256 & 235152 & 27 & 1518015 \\
\hline Number of products & 669 & 5.10 & 5.23 & 0 & 28 \\
\hline Patents & 581 & 2.19 & 5.52 & 0 & 59 \\
\hline Sales growth & 237 & 0.026 & 0.382 & -1.783 & 2.103 \\
\hline Empl growth & 199 & 0.037 & 0.391 & -0.693 & 4.868 \\
\hline Assets growth & 213 & 0.067 & 0.398 & -0.762 & 3.754 \\
\hline
\end{tabular}


However, a limitation of our study, that should be borne in mind, is that we have a relatively small number of observations for new product introductions (which may hinder our estimates from attaining high degrees of statistical significance). Furthermore, since we do not attempt to untangle the complex endogeneity between new product introductions and firm growth (Balasubramanian and Sividasan, 2011), we underline that our estimates pertain to associations rather than causal effects.

Table A1 in the appendix explores the correlations between our key variables: new product introductions, and growth of employees, assets, and sales. The correlations between the different growth indicators is far from perfect, which confirms that these variables can be included in the same regression without raising concerns about excessive collinearity (following Coad, 2010).

Figure 1 investigates the growth rates of employment, assets, and sales, in the years surrounding a new product introduction. For these figures, we focus only on the two years before or after a new product introduction, focusing only on those cases where a second product introduction event did not occur within this temporal window. These plots show some slight fluctuations around the year of the product introduction. Concerning employment growth, this appears to be relatively high in the year preceding a product introduction, and then decreasing in the year of diversification as well as the year after that. We take this as weak support of Hypotheses 1a, 2a and 3a, although to this end we will also apply more rigorous quantitative techniques. Growth of assets seems to steadily increase up to the year of diversification, after which it decreases slightly in the year after diversification (although it bounces up again two years after diversification). This offers some support for Hypotheses $1 \mathrm{~b}, 2 \mathrm{~b}$ and $3 \mathrm{~b}$. Growth of sales is observed to be low in the year before diversification, then rises in the year of diversification, before decreasing the year after. This is consistent with Hypotheses $1 \mathrm{c}$ and 2c, although it appears to be at odds with Hypothesis 3c.

We pursue our analysis estimating probit regressions (see Table 3), where the dependent variable is whether a firm introduces 1 or more products in a given year. ${ }^{12}$ As control variables, we include age and age-squared, lagged size (measured in terms of the natural logarithm of employees), and the natural logarithm of patents. To control for regional factors, we do not include regional dummies (we have a relatively large number of regions) but we include a variable that is an integer count of the number of Universities of Applied Science, as well as two agglomeration indicators (i.e. an integer count of the number of firms in the same region in the same year, and population

\footnotetext{
12 Our variable for product introduction is a count data variable (non-negative integers corresponding to the number of new product introductions: most firms have zero product introductions, and the vast majority of those firms with positive product introductions have just one, although the maximum number of product introductions in one year was 10). When we estimated poisson, negative binomial and zeroinflated negative binomial models, they did not converge and we did not obtain meaningful output. Therefore, we focus instead on converting our product introduction variable into a binary variable: taking the value 0 if there was no product introduction and 1 if there was 1 or more product introduction.
} 
density, taking logs in both cases); and furthermore we cluster our standard errors at the regional level. Year dummies are also included in some specifications.

Looking at the relationship between new product introductions and lagged growth, we see that product introductions benefit from employment growth in the previous year. This provides some support for Hypotheses 1a, and suggests that team-building occurs during the stages of planning and preparation for new product introductions. However, there are no significant results for hypotheses $1 \mathrm{~b}$ and $1 \mathrm{c}$. There is evidence that new product introductions (at time $t$ ) are associated with growth of assets (over the period t-1:t) in columns (5) and (6), which supports Hypothesis 2b. Weak support for Hypothesis 2c can be found in column (3) regarding the positive association between new product introductions and contemporaneous growth of sales.

Table 3 also shows that larger firms are more likely to engage in product introductions (looking at the coefficients on lagged log(employees) or number of products).

The interpretation of the probit coefficient estimates in Table 3 is not trivial, because probit is a non-linear model. A better understanding of the marginal effects of these estimates can be found in Table A2 in the Appendix, where we report the probit marginal effects at the means of the independent variables. Table A2 also contains coefficients from an OLS linear probability model (OLS-LPM, see Angrist and Pischke, 2009, chapter 3). The probit marginal effects at the means for the main variables of interest (growth of employment, assets or sales) are not significant, which indicates that our results should be taken with great caution. OLS-LPM estimates can also play a useful role (Angrist and Pischke, 2008), because we are not interested in generating predicted values (that might lie outside the limited dependent variable (LDV) boundaries) but in understanding the marginal effects. OLS-LPM estimates are significant in some cases, offering support to Hypotheses $1 \mathrm{a}$ and 1c. Taken together, our strongest and most significant result so far seems to be that new product introductions are preceded by employment growth in the previous period (in accord with Hypothesis 1a). 
Figure 1: box plots of employment growth (top left), assets growth (top right) and sales growth (bottom) in the years surrounding a new product introduction.
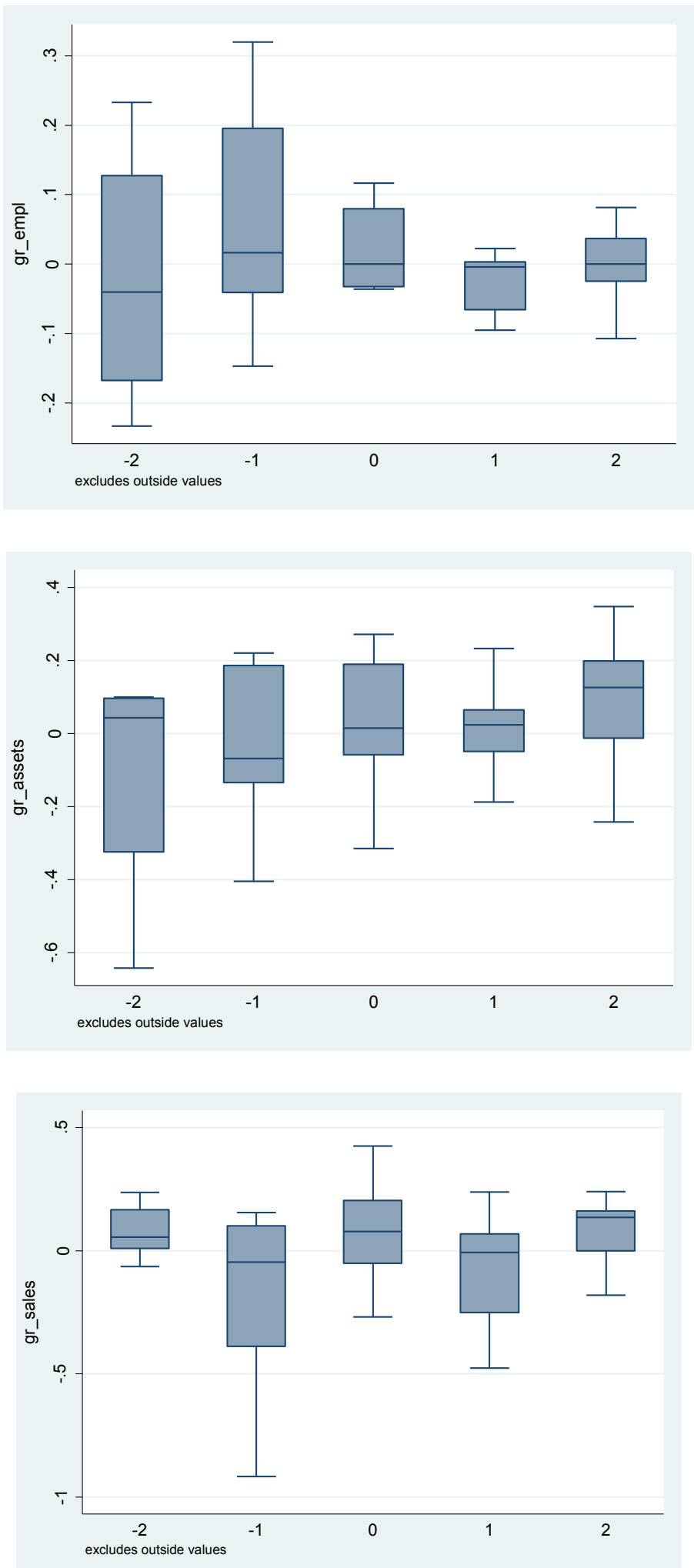
Table 3: Probit regression results. Dependent variable: a dummy for $>=1$ new product introductions. Standard errors clustered at the regional level. Key to significance stars: ${ }^{* * *}$ $\mathrm{p}<0.01,{ }^{* *} \mathrm{p}<0.05,{ }^{*} \mathrm{p}<0.1$

\begin{tabular}{|c|c|c|c|c|c|c|}
\hline & (1) & (2) & (3) & (4) & (5) & (6) \\
\hline VARIABLES & Prod intro & Prod intro & Prod intro & Prod intro & Prod intro & Prod intro \\
\hline & & & & & & \\
\hline \multirow[t]{2}{*}{ I_gr_empl } & $1.453^{* * *}$ & 2.702 & & & $1.719^{* * *}$ & $3.006^{* * *}$ \\
\hline & $(0.210)$ & $(2.381)$ & & & $(0.383)$ & $(0.818)$ \\
\hline \multirow[t]{2}{*}{ I_gr_assets } & 0.150 & -0.694 & & & 0.153 & 0.0539 \\
\hline & $(0.650)$ & (1.379) & & & $(0.527)$ & $(0.930)$ \\
\hline \multirow[t]{2}{*}{ I_gr_sales } & -0.650 & $-0.584^{*}$ & & & -0.398 & 0.846 \\
\hline & $(0.397)$ & $(0.355)$ & & & $(0.534)$ & $(1.178)$ \\
\hline \multirow[t]{2}{*}{ gr_empl } & & & -0.155 & -0.682 & -0.749 & $-5.662^{* *}$ \\
\hline & & & $(0.210)$ & $(0.724)$ & $(0.487)$ & (2.799) \\
\hline \multirow[t]{2}{*}{ gr_assets } & & & 0.299 & -0.323 & $1.778^{* * *}$ & $3.096^{* * *}$ \\
\hline & & & $(0.453)$ & $(0.597)$ & $(0.674)$ & $(1.161)$ \\
\hline \multirow[t]{2}{*}{ gr_sales } & & & 0.443 & 0.711 & 0.297 & 1.599 \\
\hline & & & $(0.276)$ & $(0.492)$ & $(0.408)$ & $(1.046)$ \\
\hline \multirow[t]{2}{*}{ age } & 0.0160 & 0.0183 & -0.00640 & $-0.0295^{* * *}$ & 0.0190 & -0.0316 \\
\hline & $(0.0162)$ & $(0.0129)$ & $(0.00674)$ & $(0.00844)$ & $(0.0149)$ & $(0.0200)$ \\
\hline \multirow[t]{2}{*}{ age squared } & $-6.30 e-05$ & $-6.81 e-05$ & $3.58 \mathrm{e}-05$ & $0.000163^{* *}$ & $-6.88 \mathrm{e}-05$ & $0.000204^{* *}$ \\
\hline & $(4.74 \mathrm{e}-05)$ & $(4.85 e-05)$ & $(2.87 e-05)$ & $(4.15 e-05)$ & $(4.35 e-05)$ & $(8.43 e-05)$ \\
\hline \multirow[t]{2}{*}{ I_log_empl } & & & $0.167^{* *}$ & $0.254^{*}$ & & \\
\hline & & & $(0.0684)$ & $(0.142)$ & & \\
\hline \multirow[t]{2}{*}{ |2_log_empl } & $0.499^{* * *}$ & 0.584 & & & $0.552^{* *}$ & $0.971^{*}$ \\
\hline & $(0.114)$ & $(0.384)$ & & & $(0.231)$ & $(0.572)$ \\
\hline \multirow[t]{2}{*}{ I_log_patents } & & $0.665^{* * *}$ & & 0.176 & & $0.696^{* * *}$ \\
\hline & & $(0.126)$ & & $(0.143)$ & & $(0.233)$ \\
\hline \multirow[t]{2}{*}{ Univ Appl Sci } & $0.227^{* * *}$ & $0.291^{* * *}$ & 0.0261 & 0.0454 & $0.237^{* *}$ & $0.403^{* * *}$ \\
\hline & $(0.0868)$ & $(0.113)$ & $(0.0363)$ & $(0.0591)$ & $(0.115)$ & $(0.130)$ \\
\hline \multirow[t]{2}{*}{ log_agglom } & & & 0.118 & 0.234 & & \\
\hline & & & $(0.0908)$ & ( $(0.165)$ & & \\
\hline \multirow[t]{2}{*}{ I_log_agglom } & $0.442^{* * *}$ & $0.623^{*}$ & & & $0.475^{* *}$ & $0.442^{* *}$ \\
\hline & $(0.101)$ & $(0.324)$ & & & $(0.193)$ & $(0.207)$ \\
\hline \multirow[t]{2}{*}{ log_popdens } & $-1.371^{* *}$ & $-1.697^{* *}$ & -0.148 & -0.395 & $-1.540^{* *}$ & $-2.412^{* * *}$ \\
\hline & $(0.580)$ & $(0.808)$ & $(0.251)$ & $(0.245)$ & $(0.776)$ & $(0.822)$ \\
\hline year dummies & no & yes & no & yes & no & yes \\
\hline \multirow[t]{2}{*}{ Constant } & -1.784 & -1.794 & $-2.862^{*}$ & -1.458 & -1.832 & 0.280 \\
\hline & $(3.491)$ & (3.177) & (1.499) & $(2.215)$ & (3.553) & $(2.441)$ \\
\hline Observations & 472 & 169 & 630 & 243 & 409 & 145 \\
\hline Pseudo-R2 & 0.4106 & 0.5698 & 0.0886 & 0.2145 & 0.4432 & 0.6433 \\
\hline
\end{tabular}

Table 4 investigates Hypotheses 3a, $3 \mathrm{~b}$ and $3 \mathrm{c}$ by presenting regression estimates of the effects of $1+$ product introductions on subsequent growth of employment, sales, and assets. ${ }^{13}$ Employment growth is negatively associated with a new product introduction

13 The attentive reader will have noticed that Table 3 reports different numbers of observations for each of our three growth indicators (employees, assets, and sales). We were therefore concerned that different 
in the previous period, which offers support for Hypothesis 3a. Assets growth is positively related to new product introductions in the previous two years (see columns (3) and (4)), which is consistent with Hypothesis 3b. Indeed, the fact that firms experience assets growth even in the year after diversification could be because it takes time for firms to accumulate the capital stock required by the introduction of new products - firms may have to keep investing in new assets even after the product has been formally introduced. Sales growth is negatively associated with previous product introductions, which goes against Hypothesis 3c. It appears that the benefits in terms of sales growth from new product introductions are less certain than we hypothesized, perhaps because market penetration is slow. Furthermore, it could be that new product introductions are associated with withdrawals from other established submarkets (if firms drop old products when they introduce new products), as if firms use diversification events to refocus their activities (some evidence in favour of this can be found in Balasubramanian and Sividasan, 2011). Therefore, if the sales from the new products are not immediately large enough to compensate for a possible decline in sales of established or withdrawn products, it might take some time for new product introductions to result in an overall positive effect on total sales.

In addition to our baseline OLS analysis, we also undertook some panel Fixed Effects (FE) and Random Effects (RE) regressions. Hausman tests were not unequivocal as to which we should prefer. FE and RE estimates contain many insignificant results, although some findings can be briefly mentioned here. FE estimates find that new product introductions are (marginally) negatively associated with subsequent employment growth (consistent with Hypothesis 3a) and positively associated with subsequent assets growth (in line with Hypothesis $3 \mathrm{~b}$ and our earlier estimates). RE estimates show that new product introductions are positively associated with subsequent assets growth and also sales growth (similar to our previous empirical findings in Table 4).

In a further robustness analysis, we undertook propensity-score matching to estimate the effect of $>=1$ new product introductions on subsequent growth of sales, employment and assets. The results obtained mirror those in Table 4. The effect of Product introduction $(t)$ on employment growth $(t+1)$ yielded a (poorly determined) negative ATT (Average Treatment effect on the Treated), in line with Hypothesis 3a. Furthermore, the effect of product introduction $(t)$ on sales growth $(t+1)$ yielded a negative and significant ATT, which goes against Hypothesis 3c but confirms our OLS findings. We could not find any significant estimates concerning growth of assets, nor when considering the second lag of growth.

numbers of observations for each growth indicator might invalidate somewhat our results, because they would not be directly comparable. To investigate this issue, we re-estimated Table 3 with the extra condition that we only focus on firm-year observations where we have (non-missing) observations for growth of employees AND growth of sales AND growth of assets. This analysis (available from the authors upon request) gave similar results, although slightly less significant in some cases (no doubt because of the smaller number of observations). We are grateful to an anonymous referee for drawing this to our attention. 
The finding that growth of sales is negatively associated with diversification in the previous year is rather puzzling, and runs counter to our hypothesis, although we can offer a few explanations. First, it may be that attempts at diversification are not successful (because diversification is an uncertain and challenging endeavour) and so unsuccessful firms may face decline after unsuccessful diversification, i.e. commercialization of a new product. Second, diversification may represent an evolutionary shift in a firm's product portfolio (Chang, 1998) such that a new product introduction might be followed by corporate refocusing that leads to exit from a previous submarket (and hence a decrease in total sales). Balasubramanian and Sividasan (2011) observe a difference between a firm's gross and net number of products around the time of patenting, and write that their evidence "suggests that patenting firms retire some products around the time new products are introduced"(p.137).

Table 4: OLS regressions, where the dependent variable is annual growth rate. Standard errors clustered at the region level. Key to significance stars: ${ }^{* *} \mathrm{p}<0.01,{ }^{* *} \mathrm{p}<0.05,{ }^{*} \mathrm{p}<0.1$

\begin{tabular}{|c|c|c|c|c|c|c|}
\hline & (1) & (2) & (3) & (4) & (5) & (6) \\
\hline VARIABLES & gr_empl & gr_empl & gr_assets & gr_assets & gr_sales & gr_sales \\
\hline \multirow[t]{2}{*}{ L.prodintrodummy } & $-0.0878^{* *}$ & $-0.0890^{* *}$ & 0.0231 & $0.0433^{* *}$ & $-0.185^{* *}$ & $-0.154^{* *}$ \\
\hline & $(0.0391)$ & $(0.0439)$ & $(0.0376)$ & $(0.0204)$ & $(0.0839)$ & $(0.0657)$ \\
\hline \multirow[t]{2}{*}{ L2. prodintrodummy } & -0.0151 & -0.0146 & $0.0957^{* * *}$ & 0.0498 & 0.146 & 0.136 \\
\hline & $(0.0202)$ & $(0.0233)$ & $(0.0326)$ & $(0.0328)$ & $(0.0963)$ & $(0.116)$ \\
\hline \multirow[t]{2}{*}{ age } & 0.000191 & 0.000334 & -0.000227 & -0.000600 & -0.000600 & -0.000670 \\
\hline & $(0.000838)$ & $(0.000996)$ & $(0.000865$ & $5)(0.000925)$ & $(0.00102)$ & $(0.00112)$ \\
\hline \multirow[t]{2}{*}{ age squared } & $4.12 \mathrm{e}-07$ & $-8.30 e-07$ & $4.00 \mathrm{e}-07$ & $1.83 e-06$ & $4.82 e-06$ & $4.88 \mathrm{e}-06$ \\
\hline & $(4.61 e-06)$ & $(5.19 \mathrm{e}-06)$ & $(4.74 \mathrm{e}-06$ & ) $(4.97 e-06)$ & $(6.14 e-06)$ & )$(6.51 e-06$ \\
\hline \multirow[t]{2}{*}{ I_log_empl } & $-0.0194^{*}$ & -0.0198 & -0.00542 & -0.00240 & -0.00745 & -0.0103 \\
\hline & $(0.00993)$ & $(0.0122)$ & $(0.00741)$ & $(0.00953)$ & $(0.00771)$ & $(0.0117)$ \\
\hline \multirow[t]{2}{*}{ Univ Appl Sci } & 0.000598 & -0.000804 & -0.00113 & 0.000271 & -0.000670 & -0.000763 \\
\hline & $(0.00162)$ & $(0.00134)$ & $(0.00228)$ & $(0.00237)$ & $(0.00272)$ & $(0.00300)$ \\
\hline \multirow[t]{2}{*}{ log_agglom } & -0.00125 & -0.0122 & $-0.0157^{*}$ & -0.0130 & $-0.0155^{*}$ & $-0.0168^{*}$ \\
\hline & $(0.00779)$ & $(0.00760)$ & $(0.00903)$ & $(0.0109)$ & $(0.00875)$ & $(0.00924)$ \\
\hline \multirow[t]{2}{*}{ log_popdens } & -0.0143 & -0.00449 & $0.0254^{*}$ & 0.0205 & 0.0101 & 0.00768 \\
\hline & $(0.0116)$ & $(0.00931)$ & $(0.0137)$ & $(0.0149)$ & $(0.0180)$ & $(0.0199)$ \\
\hline \multirow[t]{2}{*}{ I_log_patents } & & $0.0235^{* * *}$ & & 0.00606 & & 0.0368 \\
\hline & & $(0.00789)$ & & $(0.0151)$ & & $(0.0256)$ \\
\hline year dummies & no & yes & no & yes & no & yes \\
\hline \multirow[t]{2}{*}{ Constant } & $0.173^{*}$ & $0.178^{*}$ & 0.0150 & -0.0651 & 0.0995 & 0.151 \\
\hline & $(0.0913)$ & $(0.0949)$ & $(0.0908)$ & $(0.145)$ & $(0.101)$ & '(0.153) \\
\hline Observations & 1,102 & 939 & 796 & 691 & 1,020 & 884 \\
\hline R-squared & 0.013 & 0.045 & 0.006 & 0.086 & 0.012 & 0.099 \\
\hline
\end{tabular}




\section{CONCLUSION}

Within this paper we look at leads and lags of diversification events. Of course, diversification is not solely induced by exogenous factors, but rather represents the result of long-term firm internal planning. Therefore, we argue that understanding the firm growth - innovation/diversification linkage requires to pay attention to the following two aspects in empirical analyses. First, when investigating the question in how far diversification, as one form of innovation, leads to firm growth, the respective growth indicators have to be considered before, during and after the diversification event to capture all parts of their interrelationship. Second, our paper highlights a need to distinguish between different types of growth. We observed that a new product introduction had a significant positive effect on subsequent growth of assets, while also having a significant negative effect on employment growth (Table 4). This does not fit well with previous work that takes growth of employment and assets as interchangeable indicators of growth, although it does fit well with our theory. Moreover, we hypothesize and find that employment growth actually precedes diversification as executing the planned expansion requires the integration of new managerial resources and competences also already before the event as advocated by Penrose (1959), but not necessarily predicted by the generally observed random walk of firm growth.

Given these theoretical reconsiderations and first empirical indications future work on firm growth would do well to generally distinguish between these different dimensions of growth as well as its development before, during and after the diversification event. As regards empirical analyses in particular, four prosperous avenues for future research are paved. First of all, there is clearly the need to provide further empirical investigations incorporating other sectors, potentially considering growing but also declining industries. While there are advantages of studies such as ours that focus on specific industries, there are also concerns about external validity and our ability to generalize. Furthermore, our investigation of the machine tools industry (which can be considered to be a mature, and perhaps declining, industry where new product introductions are relatively infrequent) could be complemented by insights from other industries. Databases with a large number of observations for new product introductions would also be especially valuable. Second, while our analysis focuses on one specific mode of diversification, future research could enhance our understanding of the proposed relationships by investigating alternative modes of diversification, such as M\&A activities or internationalization steps, and their effects on growth in the outlined indicators before, during and after the diversification event. A comparison of these different modes would be very fruitful. Third, a deeper understanding of the qualitative dimension of employment growth at different stages of the diversification process seems to be fruitful. Perhaps linked employer-employee databases offer the possibility to inform us whether human resource acquisition prior to diversification 
primarily happens on the level of white collar workers as theory suggests, while after diversification the focus is on blue collar workers to help execute prior plans. Fourth, further work could possibly apply a more sophisticated (structural) system of equations in order to better estimate the causal relations between the variables. 


\section{REFERENCES}

Achtenhagen L, Naldi L, Melin L (2010) "'Business growth" - Do practitioners and scholars really talk about the same thing?" Entrepreneurship Theory and Practice, March, 289-316.

Angrist, J., Pischke, J.-S., (2009). Mostly Harmless Econometrics: An Empiricist's Companion. Princeton: Princeton University Press.

Balasubramanian N., Sivadasan J., (2011). What happens when firms patent? New evidence from US Economic Census Data. Review of Economics and Statistics 93 (1), 126-146.

Brown, R. and Mawson, S. (2013). 'Trigger Points and High Growth Firms: A Conceptualisation and Review of Public Policy Implications.' Journal of Small Business and Entrepreneurship Development, 20 (2), 279-295.

Buenstorf, G. and S. Klepper (2009). Heritage and agglomeration: the Akron tyre cluster revisited. The Economic Journal, 119: 705-733.

Buenstorf, G. and C. Guenther (2011). No place like home? Location choice and firm survival after forced relocation in the German machine tool industry, Industrial and Corporate Change, 20: 1-28.

Chang, S.J., (1998) An evolutionary perspective on diversification and corporate restructuring: entry, exit, and economic performance during 1981--89. Strategic Management Journal 17 (8), 587-611.

Coad, A. (2009). The Growth of Firms: A Survey of Theories and Empirical Evidence. Edward Elgar: Cheltenham, UK.

Coad A, (2010). "Exploring the processes of firm growth: Evidence from a vector autoregression", Industrial and Corporate Change, 19(6), 1677-1703.

Coad A and Guenther C (2013). "Diversification patterns and survival as firms mature." Small Business Economics, 41, 633-649.

Delmar, F. (1997), 'Measuring growth: methodological considerations and empirical results', in R. Donckels and A. Miettinen (eds), Entrepreneurship and SME Research: On its Way to the Next Millennium, Aldershot, VA: Avebury, pp. 190-216.

Falck, O., Guenther C. , Heblich S., and W. R. Kerr. (2013) "From Russia with Love: The Impact of Relocated Firms on Incumbent Survival." Journal of Economic Geography, 13(3), 419-449.

Fornahl, D. and C. Guenther (2010). Persistence and Change of Regional Industrial Activities: The Impact of Diversification in the German Machine Tool Industry.' European Planning Studies, 18(12), 1911-1936.

Foster L., Haltiwanger J., Krizan C. J., (2006). Market selection, reallocation, and restructuring in the US retail trade sector in the 1990s. Review of Economics and Statistics 88 (4), 748-758. 
Fritsch, M. and C. Schwirten (1999). Enterprise-University Co-operation and the Role of Public Research Institutions in Regional Innovation Systems, Industry and Innovation, 6:69-83.

Geroski P. and K. Gugler (2004) "Corporate Growth Convergence in Europe" Oxford Economic Papers 56 (2004) 597-620.

Haltiwanger, J.C., Jarmin, R.S. and Miranda, J. (2013), Who creates jobs? Small vs. large vs. young, Review of Economics and Statistics forthcoming.

Huber, P., Oberhofer, H. and Pfaffermayr, M. (2012a), Job creation and the intra-distribution dynamics of the firm size distribution, Working Papers in Economics and Finance 2012-05, University of Salzburg

Huber, P., Oberhofer, H. and Pfaffermayr, M. (2012b), Who creates jobs? Estimating job creation rates at the firm level, WIFO Working Papers No. 435, Austrian Institute of Economic Research

Jacobs, J., 1969, The Economy of Cities, New York: Vintage Books.

Klepper, S. and Sleeper, S. (2005). Entry by Spinoffs, Management Science, 51, 1291-1306.

Lockett A, Wiklund J, Davidsson P, Girma S (2011) "Organic and acquisitive growth: reexamining, testing and extending Penrose's growth theory" Journal of Management Studies $48: 1,48-74$.

Marshall, A. (1920): Principles of Economics, $8^{\text {th }}$ ed. London: Macmillan.

McKelvie A., Wiklund J., (2010), "Advancing Firm Growth Research: A Focus on Growth Mode Instead of Growth Rate”, Entrepreneurship Theory and Practice, 34(2), 261-288.

Neffke F., Henning M., (2013). Skill relatedness and firm diversification. Strategic Management Journal 34, 297-316.

Oberhofer, H. and Pfaffermayr, M. (2013), Firm growth in multinational corporate groups, Empirical Economics forthcoming.

Palich, L. E., Cardinal, L. B. and C.C. Miller (2000). Curvilinearity in the diversificationperformance linkage: An examination of ever three decades of research, Strategic Management Journal, 21: 155-174.

Penrose, E. T. (1959) [1995]. The Theory of the Growth of the Firm, Oxford: Oxford University Press

Rawley, Evan. (2010). Diversification, Coordination Costs and Organizational Rigidity: Evidence from Microdata. Strategic Management Journal, 31(8): 873-891.

VDMA (Verband Deutscher Maschinen- und Anlagenbau e.V.) (ed.)(various years). Wer baut Maschinen. Frankfurt/Main. 


\section{APPENDICES}

Table A1: Matrix of contemporaneous correlations for the key variables

\begin{tabular}{|c|c|c|c|c|}
\hline & Prod Intro & gr_sales & gr_empl & gr_assets \\
\hline Prod Intro & 1 & & & \\
\hline \multicolumn{5}{|l|}{ p-value } \\
\hline No. obs. & 3827 & & & \\
\hline gr_sales & 0.0245 & 1 & & \\
\hline p-value & 0.4135 & & & \\
\hline No. obs. & 1116 & 2876 & & \\
\hline gr_empl & -0.0065 & 0.1395 & 1 & \\
\hline p-value & 0.8434 & 0.0000 & & \\
\hline No. obs. & 926 & 2228 & 2598 & \\
\hline gr_assets & 0.0175 & 0.3678 & 0.1848 & 1 \\
\hline p-value & 0.5808 & 0.0000 & 0.0000 & \\
\hline No. obs. & 1003 & 2187 & 1905 & 2674 \\
\hline
\end{tabular}


Table A2: Investigating the marginal effects associated with the probit estimates in Table 3. Key to significance stars: ${ }^{* * *} \mathrm{p}<0.01,{ }^{* *} \mathrm{p}<0.05,{ }^{*} \mathrm{p}<0.1$

\begin{tabular}{|c|c|c|c|c|c|c|c|c|c|c|c|c|}
\hline & (1) & (2) & (3) & (4) & (5) & (6) & (7) & (8) & (9) & $(10)$ & (11) & (12) \\
\hline \multirow[t]{2}{*}{ VARIABLES } & Prod intro & Prod intro & Prod intro & Prod intro & Prod intro & Prod intro & Prod intro & Prod intro & Prod intro & Prod intro & Prod intro & Prod intro \\
\hline & Probit MFX & Probit MFX & Probit MFX & Probit MFX & Probit MFX & Probit MFX & OLS & OLS & OLS & OLS & OLS & OLS \\
\hline \multirow[t]{2}{*}{ I_gr_empl } & 0.00179 & 0.00273 & & & 0.000789 & $1.90 \mathrm{e}-05$ & $0.0909^{*}$ & $0.145^{* * *}$ & & & $0.124^{* *}$ & $0.157^{* * *}$ \\
\hline & $(0.00160)$ & $(0.00441)$ & & & $(0.00109)$ & $(9.74 \mathrm{e}-05)$ & $(0.0490)$ & $(0.0399)$ & & & $(0.0491)$ & $(0.0334)$ \\
\hline \multirow[t]{2}{*}{ I_gr_assets } & 0.000185 & -0.000701 & & & $7.01 \mathrm{e}-05$ & $3.41 \mathrm{e}-07$ & 0.0207 & 0.00168 & & & 0.0129 & 0.00323 \\
\hline & $(0.000841)$ & $(0.00235)$ & & & $(0.000180)$ & $(5.16 \mathrm{e}-06)$ & $(0.0182)$ & $(0.0157)$ & & & $(0.0104)$ & $(0.0110)$ \\
\hline \multirow[t]{2}{*}{ I_gr_sales } & -0.000800 & -0.000590 & & & -0.000182 & $5.35 \mathrm{e}-06$ & $-0.0311^{*}$ & $-0.0257^{* *}$ & & & -0.0340 & $-0.0228^{*}$ \\
\hline & $(0.000951)$ & $(0.00104)$ & & & $(0.000485)$ & $(2.38 \mathrm{e}-05)$ & $(0.0182)$ & $(0.0124)$ & & & $(0.0206)$ & $(0.0123)$ \\
\hline \multirow[t]{2}{*}{ gr_empl } & & & -0.00359 & -0.0189 & -0.000343 & $-3.58 e-05$ & & & -0.00169 & -0.00210 & 0.0182 & 0.0222 \\
\hline & & & $(0.00489)$ & $(0.0196)$ & $(0.000610)$ & $(0.000176)$ & & & $(0.00495)$ & $(0.0112)$ & $(0.0316)$ & $(0.0387)$ \\
\hline \multirow[t]{2}{*}{ gr_assets } & & & 0.00692 & -0.00899 & 0.000816 & $1.96 \mathrm{e}-05$ & & & 0.00573 & -0.000841 & 0.00583 & -0.00190 \\
\hline & & & $(0.0109)$ & $(0.0175)$ & $(0.00109)$ & $(0.000102)$ & & & $(0.0119)$ & $(0.0118)$ & $(0.00876)$ & $(0.0107)$ \\
\hline \multirow[t]{2}{*}{ gr_sales } & & & 0.0103 & 0.0198 & 0.000136 & $1.01 \mathrm{e}-05$ & & & 0.0151 & 0.0126 & 0.00256 & -0.00487 \\
\hline & & & $(0.00690)$ & $(0.0178)$ & $(0.000232)$ & $(4.87 e-05)$ & & & $(0.0118)$ & $(0.0151)$ & $(0.00888)$ & $(0.0103)$ \\
\hline \multirow[t]{2}{*}{ age } & $1.97 e-05$ & $1.85 \mathrm{e}-05$ & -0.000148 & -0.000820 & $8.70 \mathrm{e}-06$ & $-1.99 e-07$ & $8.38 \mathrm{e}-05$ & $7.87 e-05$ & -0.000418 & -0.000476 & -0.000139 & -0.000142 \\
\hline & $(1.72 \mathrm{e}-05)$ & $(3.14 \mathrm{e}-05)$ & $(0.000192)$ & $(0.000513)$ & $(1.56 \mathrm{e}-05)$ & $(1.04 \mathrm{e}-06)$ & $(0.000302)$ & $(0.000346)$ & $(0.000345)$ & $(0.000360)$ & $(0.000374)$ & $(0.000336)$ \\
\hline \multirow[t]{2}{*}{ age squared } & $-7.75 e-08$ & $-6.87 e-08$ & $8.29 \mathrm{e}-07$ & $4.53 e-06^{*}$ & $-3.16 e-08$ & $1.29 \mathrm{e}-09$ & $3.85 \mathrm{e}-07$ & $1.34 \mathrm{e}-07$ & $2.65 e-06$ & $3.04 \mathrm{e}-06$ & $1.94 \mathrm{e}-06$ & $1.99 \mathrm{e}-06$ \\
\hline & $(5.51 e-08)$ & $(1.02 \mathrm{e}-07)$ & $(8.38 \mathrm{e}-07)$ & $(2.58 \mathrm{e}-06)$ & $(4.63 e-08)$ & $(6.68 \mathrm{e}-09)$ & $(1.78 \mathrm{e}-06)$ & $(1.80 e-06)$ & $(2.18 \mathrm{e}-06)$ & $(2.22 \mathrm{e}-06)$ & $(2.45 e-06)$ & $(2.07 e-06)$ \\
\hline \multirow[t]{2}{*}{ I_log_empl } & & & $0.00387^{* *}$ & $0.00706^{*}$ & & & & & $0.00591^{* *}$ & 0.00514 & & \\
\hline & & & $(0.00183)$ & $(0.00406)$ & & & & & $(0.00290)$ & $(0.00368)$ & & \\
\hline \multirow[t]{2}{*}{ I2_log_empl } & 0.000614 & 0.000590 & & & 0.000253 & $6.14 \mathrm{e}-06$ & $0.00833^{*}$ & 0.00353 & & & $0.00817^{*}$ & 0.00225 \\
\hline & $(0.000567)$ & $(0.000792)$ & & & $(0.000310)$ & $(2.99 e-05)$ & $(0.00472)$ & $(0.00488)$ & & & $(0.00424)$ & $(0.00578)$ \\
\hline \multirow[t]{2}{*}{ Univ Appl Sci } & 0.000279 & 0.000293 & 0.000606 & 0.00126 & 0.000109 & $2.55 \mathrm{e}-06$ & $0.00330^{* *}$ & $0.00391^{* *}$ & 0.000927 & 0.00163 & $0.00277^{*}$ & $0.00351^{*}$ \\
\hline & $(0.000293)$ & $(0.000472)$ & $(0.000863)$ & $(0.00174)$ & $(0.000154)$ & $(1.30 \mathrm{e}-05)$ & $(0.00157)$ & $(0.00172)$ & $(0.00105)$ & $(0.00113)$ & $(0.00145)$ & $(0.00186)$ \\
\hline \multirow[t]{2}{*}{ I_log_patents } & & 0.000672 & & 0.00490 & & $4.40 \mathrm{e}-06$ & & $0.0257^{*}$ & & 0.00443 & & 0.0135 \\
\hline & & $(0.00129)$ & & $(0.00493)$ & & $(2.37 e-05)$ & & $(0.0129)$ & & $(0.00975)$ & & $(0.0155)$ \\
\hline \multirow[t]{2}{*}{ log_agglom } & & & 0.00272 & 0.00650 & & & & & 0.00330 & 0.00397 & & \\
\hline & & & $(0.00191)$ & $(0.00514)$ & & & & & $(0.00214)$ & $(0.00275)$ & & \\
\hline \multirow[t]{2}{*}{ I_log_agglom } & 0.000544 & 0.000629 & & & 0.000218 & $2.79 e-06$ & $0.00764^{* *}$ & $0.00875^{* *}$ & & & $0.00749^{* *}$ & $0.00805^{*}$ \\
\hline & $(0.000493)$ & $(0.000966)$ & & & $(0.000298)$ & $(1.47 e-05)$ & $(0.00328)$ & $(0.00422)$ & & & $(0.00347)$ & $(0.00441)$ \\
\hline \multirow[t]{2}{*}{ log_popdens } & -0.00169 & -0.00171 & -0.00343 & -0.0110 & -0.000706 & $-1.52 \mathrm{e}-05$ & $-0.0113^{*}$ & $-0.0169^{* *}$ & -0.00322 & -0.00657 & -0.0128 & $-0.0154^{*}$ \\
\hline & $(0.00179)$ & $(0.00269)$ & $(0.00618)$ & $(0.00941)$ & $(0.000999)$ & $(7.76 e-05)$ & $(0.00615)$ & $(0.00784)$ & $(0.00704)$ & $(0.00713)$ & $(0.00782)$ & $(0.00839)$ \\
\hline year dummies & no & yes & no & yes & no & yes & no & yes & no & yes & no & yes \\
\hline \multirow{2}{*}{ Constant } & & & & & & & -0.0252 & -0.0291 & -0.00738 & -0.0332 & -0.00962 & -0.0390 \\
\hline & & & & & & & $(0.0368)$ & $(0.0505)$ & $(0.0422)$ & $(0.0408)$ & $(0.0402)$ & $(0.0504)$ \\
\hline Observations & 472 & 169 & 630 & 243 & 409 & 145 & 472 & 408 & 630 & 545 & 409 & 355 \\
\hline (Pseudo)-R2 & 0.4106 & 0.5698 & 0.0886 & 0.2145 & 0.4432 & 0.6433 & 0.102 & 0.190 & 0.015 & 0.052 & 0.138 & 0.223 \\
\hline
\end{tabular}




\section{Recent papers in the SPRU Working Paper Series:}

SWPS 2013-01. Gabriele Pellegrino and Maria Savona. September 2013. "Is money all? Financing versus knowledge and demand constraints to innovations".

SWPS 2013-02. Adrian Smith and Sabine Hielscher. September 2013. “Grassroots digital fabrication and makerspaces: reconfiguring, relocating and recalibrating innovation".

SWPS 2013-03. Paul Nightingale and Alex Coad. September 2013. "Muppets and gazelles: political and methodological biases in entrepreneurship research".

SWPS 2013-04. Alberto Marzucchi and Sandro Montresor. September 2013. "The multidimensional additionality of innovation policies. A multi-level application to Italy and Spain".

SWPS 2013-05. Fulvio Castellacci. September 2013. "Institutional voids or entry barriers? Business groups, innovation and market development in emerging economies".

SWPS 2013-06. Tommaso Ciarli and Michele Di Maio. October 2013. "Theoretical arguments for industrialisation-driven growth and economic development".

SWPS 2013-07. William Lazonick, Mariana Mazzucato, and Öner Tulum. October 2013. “Apple's changing business model: what should the world's richest company do with all those profits?".

SWPS 2013-08. Phil Johnstone. October 2013. "Planning reform, rescaling, and the construction of the post-political: The case of The Planning Act 2008 and nuclear power consultation in the UK".

SWPS 2013-09. Mariana Mazzucato and Alan Shipman. October 2013. "Accounting for productive investment and value creation".

SWPS 2013-10. Anders Bornhäll, Sven-Olov Daunfeldt, and Niklas Rudholm. October 2013.

"Sleeping Gazelles: High profits but no growth".

\section{SPRU}

Science and Technology

Policy Research
SPRU

Science and Technology Policy Research

University of Sussex

Falmer, Brighton, BN1 9SL, UK

www.sussex.ac.uk/spru 